\title{
Upaya Menurunkan Defect Fender LH Bump Impact Fitting Unit D17d Dengan Metode PDCA di PT XYZ
}

\author{
Vitalis Anggit Wisnu Wicsksono, Annisa Mulia Rani \\ Program Studi Teknik Industri, Fakultas Teknik, Universitas Muhammadiyah Jakarta \\ Jalann Cempaka Putih Tengah 27, Jakarta Pusat 10510 \\ Email : Ankgiets.wisnu@gmail.com
}

\begin{abstract}
ABSTRAK
Dalam Industrial Engineering kualitas merupakan salah satu hal yang sangat di perhatikan dalam prosesnya, sama halnya yang dilakukan oleh PT. XYZ. Departemant Body Line 1 salah satu departemen yang ada di PT XYZ yang bertugas membuat body mobil dengan menggunakan mesin las co2 dan las spot untuk merakit. Didalam di Body Line 1 Departemen, ada beberapa masalah yang berkaitan dengan produksi yaitu masalah kualitas yang mempengaruhi defect per unit (DPU) meningkat. Ada beberapa jalur yang menyumbang tingginya defect pada body Line 1. Akan tetapi pada line metal finish adalah penyumbang defect yang paling tinggi yaitu sebesar 493 temuan defect yang didominasi defect fender Lh bump impact fitting unit D17D sebesar 294. Metal finish adalah tempat merakit door assy dan proses repair appearance di body welding, hal ini dilakukan untuk menjaga kualitas body yang akan dikirim ke Painting department, Sedangkan target kebijakan dari perusahaan adalah $0,2 \%$ defect dari total produksi sehingga perlu adanya penanggulangan agar target perusahaan tercapai.

Perbaikan yang dilakukan untuk mengatasi masalah tersebut dengan mengunakan Plan - Do - Check - Action (PDCA). Diharapkan dengan perbaikan ini dapat menurunkan defect yang sedang terjadi jalur Metal Finish D 17D. sehingga target kualitas yang sudah ditetapkan dapat tercapai.

Dari kegiatan perbaikan tersebut, defect fender bump LH impact fitting dari bulan April - September 2017 dapat diturunkan dari 294 defect menjadi 4 defect pada bulan Desember 2017. Sehingga target yang sudah ditetpakan oleh manajement telah tercapa.
\end{abstract}

Kata Kunci : Defect, PDCA,Check.

SURYA TEKNIKA Vol. 6 No. 1, Desember 2019: 48-55 


\begin{abstract}
In the industrial Enginering quality is one of the things that is very noticed in the process, as well as. In t those carried out by PT.XZ. The Body Line 1 Department is one of departements in PT.XYZ that is charge to making cars bodies using $\mathrm{Co} 2$ welding machines and spot welding machines. In the body laine departement, there are several problem related to production, namely quality problem that effect the defect/unit (DPU) increased there were several pathways that contributed to thr hight defect on body line 1 . However, one on line metal finish was the highest contect contributor, namely 493 finding of defect dominated by fender Lh Bupm impact fitting unit D17D was 294. Metal finish was the door assy adm repair appearance proses in body welding, this is done to mentain to quality of the body that will besentto the paintng departement, while the police target of the company is $0,2 \%$ of the total production so is't necessary to the overcome the company's tagets.
\end{abstract}

Improvement were made to overcome these problem by using Plan - DoCheck - Action (PDCA). It's expected that with improvemnet can reduce defect that are happening in metal finish line D17D. so that target quality can be achieved.

From the improvement activites, defect fender Lh bump impact fitting from April - September 2017canbe decrease from 294 to be 4 defect in december 2017. So that the target can be achieved.

Keywords: Defect , PDCA, Check

\section{PENDAHULUAN}

PT. XYZ adalah suatu perusahaan yang bergerak di bidang Manufactur khususnya dalam industri otomotif roda empat, Dengan meningkatnya kebutuhan masyarakat akan kendaraan bermotor yang terus bertambah di setiap tahunnya merupakan salah satu pemicu percepatan tumbuhnya Industri Otomotif kendaraan bermotor di Indonesia.

Semakin banyaknya permintaan konsumen maka perusahaan juga harus meningkatkan kapasitas produksinya, sehingga perusahaan juga harus semakin meningkatnya pula pengawasan dan pengendalian produksi terhadap kualitas produknya. Karena kepuasan pelanggan menjadi tolak ukur dari kualitas sebuah produk yang dihasilkan. Permintaan pelanggan yang terus meningkat, pembuatan produk yang terbaik, dan berkualitas tinggi dengan harga jual yang kompetitif adalah sebuah tantangan terhadap perusahaan PT.XYZ pada saat ini.

Departemant welding merupakan salah satu departemant yang berada di PT.XYZ yang bertugas membuat body mobil dengan merakit setiap bagian kendaraan dengan menggunkan mesin las. Deparemant welding memproduksi varian unit $\mathrm{D} 17 \mathrm{D}$ dan $\mathrm{D} 22 \mathrm{D}$ yang menjadi produk unggulan di PT.XYZ. Akan tetapi dari segi kualitas varian unit D17D memiliki tingkat defect (cacat)

SURYA TEKNIKA Vol. 6 No. 1, Desember 2019: 48-55 
kualitas lebih tinggi dibandingkan dengan varian unit D 22D. Departement welding sendiri sering kali mendapatkan feed back dari Quality inspection line welding akibat defect flow out dari departement welding itu sendiri. Pada 6 bulan terakhir di Quality Inspection Line welding, jumlah defect temuan proses Body Welding yang flow out (terlewat) adalah sebagai berikut :

\begin{tabular}{|c|l|c|c|}
\hline \multirow{2}{*}{ NO } & \multirow{2}{*}{ BULAN } & \multicolumn{2}{|c|}{ UNII } \\
\cline { 3 - 4 } & & D22D & D17D \\
\hline 1 & APRL & 37 & 133 \\
\hline 2 & NEI & 34 & 115 \\
\hline 3 & JUNI & 41 & 125 \\
\hline 4 & JULI & 39 & 132 \\
\hline 5 & AGUSTUS & 56 & 197 \\
\hline 6 & SEPIEMBER & 32 & 211 \\
\hline \multicolumn{2}{|c|}{ TOTALDEFECT } & 239 & 913 \\
\hline
\end{tabular}

Dari tabel diatas kita dapat melihat bahwa Defect body welding khususnya pada unit D17D lebih besar yaitu 913 defect per unit, dibandingkan dengan defect pada unit D22D yaitu sebesar 239 defect per unit. Hal ini perlu mendapatkan penanganan yang serius dan perlu dilakukan upaya untuk menurunkannya.

Defect selama bulan April sampai bulan September 2017 yang timbul pada body welding selalu tinggi, jauh melebihi target yang telah ditetapkan oleh perusahaan yaitu $\mathbf{0 , 2 \%}$ defect per unit, oleh karena itu peneliti melakukan observasi untuk mengetahui jalur manakah yang menyumbang defect terbesar yang menyebabkan timbulnya problem kualitas pada body welding. Berikut adalah data dari jalur penyumbang defect yang muncul:

\begin{tabular}{|c|c|c|c|c|c|c|}
\hline No & Libe & $\begin{array}{l}\text { Total } \\
\text { Defect }\end{array}$ & $\begin{array}{l}\text { Total } \\
\text { Iniit }\end{array}$ & 9DPt & \%Defeet & Acmst \\
\hline 1 & Meal Finish & 493 & 30164 & $1,6 \%$ & $54 \%$ & 540 \\
\hline 2 & Dnder Rear & so & 30164 & $0,2 \%$ & $5 \%$ & $59 \%$ \\
\hline 3 & Under Body. & 43 & 30164 & $0,1 \%$ & 59. & $64 \%$ \\
\hline 4 & Side Mentber & $n$ & 30164 & 0,39 & $3 \%$ & 736 \\
\hline 5 & Man Body & 68 & 30164 & $0,2 \%$ & $7 \%$ & $80 \%$ \\
\hline 6 & Shell Body & 98 & 30164 & 0,35 & 1116 & $91 \%$ \\
\hline \multirow[t]{2}{*}{7} & Under Frunt & 84 & 30161 & 0,39 & $9 \%$ & $100 \%$ \\
\hline & Total & 913 & & & & \\
\hline
\end{tabular}

Dari data diatas bahwa pada line Metal finish menyumbang defect yang paling tinggi. Metal Finish merupakan line yang merakit Door Assy dan proses repair appearance keseluruhan body welding.Adapun defect yang menjadikan line Metal Finish penyumbang defect paling tinggi antara lain:

\begin{tabular}{|c|c|c|c|c|c|c|c|c|}
\hline \multirow[b]{2}{*}{ M. } & \multirow{2}{*}{ binlibt. } & \multicolumn{7}{|c|}{ 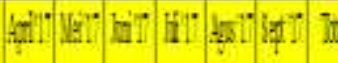 } \\
\hline & & $\mathrm{H}$ & it & if & U & is & Iit & Ziz \\
\hline & ivelebuizuth & i) & 33 & 5 & 4 & 6 & 51 & 8 \\
\hline & 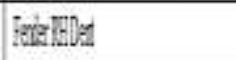 & it & 15 & it & f & ; & 1. & 6 \\
\hline 2 & 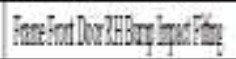 & 9 & 6 & 11 & 8 & 9 & $i$ & $\theta$ \\
\hline 1 & patentiar & B & 9 & 19 & if & ? & 4 & 3 \\
\hline & Thit & 8 & 8 & 9 & 7 & 8 & 第 & 49 \\
\hline
\end{tabular}

Dari data diatas bahwa defect penyumbang terbesar adalah defect fender Lh bump impact fitting. Menyumbang total defect sebanyak 294 defect dari total defect 493 selama bulan April - September 2017di line Metal finish. Dampak yang terjadi jika defect fender Lh bump impact fitting tidak segera ditangani akan menimbulkan dampak yang besar bagi perusahaan. Adapun dampak tersebut yang akan tibul adalah sebgai berikut:

1. Proses repair yang terjadi akan menambah biaya produksi bagi perusahaan, jika terjadi defect flow out (terlewat).

2. Pencapiaan jumlah produksi akan turun karena banyaknya unit yang delay, akibat proses repair yang berlebihan.

3. Kulitas produk akan menurun karena adanya proses repair yang berlebihan, mengingat ketebalan part fender hanya $0,67 \mathrm{~mm}$.

4. Menurunya tingkat kepercayaan pelanggan akan kualitas produk yang dihasilkan oleh PT.XYZ.

Adapun yang dimaskut dengan fender adalah suatu bagian komponen kendaraan yang terletak pada bagian 
depan samping kendaraan, berfungsi untuk melindungi konstruksi suspensi dan melindungi dari kotoran dan lumpur. Pada area fender merupakan bagian yang mencolok perhatian pelanggan, karena letaknya mudah terlihat dan menjadi bahan tarik bagi pelanggan. Oleh karena itu itu untuk kepuasan pelanggan diharuskan untuk menjaga area tersebut agar tidak membuat defect saat proses produksi.

\section{Perumusan Masalah}

1. Apakah penyebab utama defect Fender LH Bump Impact Fitting di jalur Metal Finish?

2. Perbaikan apa yang digunakan untuk menanggulangi Defect Fender LH bump Impact Fitting di jalur Metal Finish?

3. Apakah setelah melakukan perbaikan ada penurunan jumlah defect di jalur Metal finish di PT. XYZ?

Oleh sebab itu maka perlu untuk dilakukan analisis permasalahan yang berhubungan dengan kualitas dengan menggunakan metode PDCA (Plan, Do, Check, Action) dengan 8 Langkah dan 7 alat bantu didalamnya yang digunakan.

\section{Batasan penelitian}

1. Penelitian dilakukan di departement Welding PT. XYZ

2. Pengambilan data dilakukan pada bulan September 2017 dengan history data dari bulan April 2017 sampai dengan bulan September 2017.

3. Difect yang ditanggulangi adalah Apperance Fender LH unit D17D.

\section{Tujuan penelitian}

1. Mengetahui penyebab utama defect Fender LH Bump Impact Fitting di Jalur Metal Finish di PT.XYZ.

2. Menentukan cara untuk menurunkan defect Fender Lh Bump Impact Fitting di jalur Metal Finish PT. XYZ.
3. Mengetahui penurunan jumlah defect Fender Lh Bump Impact Fitting yang timbul setelah dilakukan proses perbaikan.

\section{Manfaat penelitian}

1. Dapat meningkatkan kualitas dari kegiatan perkulihaan.

2. Sebagai sarana untuk menambah pengetahuan dan wawasan dan penerapan dalam kegiatan perkulihaan.

3. Sebagai sarana improvement bagi perusahaan dalam penanggulangan kualitas, dan menjamin kualitas kerja di setiap masing- masing area kerja dengan beranggapan bahwa next proses adalah sebagai pelanggan.

\section{TINJAUAN PUSTAKA}

Siklus Deming model perbaikan berkesinambungan yang dikembangkan oleh W. Edward Deming yang terdiri dari 4 komponen seperti ada di gambar:

\section{PDCA CYCLE}

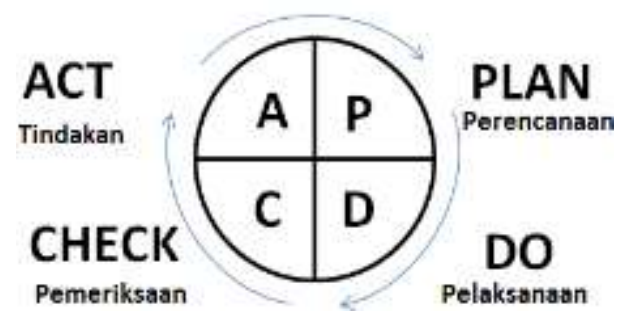

\section{METODE PENELITIAN}

Metode penelitian merupakan sebuah kerangka penelitian yang memuat tentang langkah-langkah penelitian yang akan dilakukan dalam memecahkan permasalahan yang dihadapi. Kerangka utama dalam metode penelitian memiliki fungsi sebagai pembatas dan pengendali dalam menjaga arah tata cara penulisan laporan penelitian 
agar sesuai dengan alurnya untuk mencapai tujuan yang ditetapkan, memudahkan dalam menganalisis permasalahan, dan mengurangi kesalahan dalam penulisan laporan penelitian.

Seluruh langkah-langkah dalam metode penelitian merupakan urutan dari rangkaian kegiatan dalam melakukan penelitian yang nantinya akan didapatkan hasil dari seluruh langkah-langkah tersebut, dan hasil akhir yang dapat ditarik kesimpulannya sebagai tujuan akhir dari dilakukannya penelitian.

\section{PLAN}

1. Menentukan Tema

2. Menetapkan Target

3. Analisa dan Penyebab defect appearance tinggi

4. Rencana Penanggulangan

DO

5. Penanggulangan Masalah defect appearance tinggi

CHECK

6. Memeriksa Hasil

ACTION

7. Standarisasi

8. Masalah Berikutnya

\section{HASIL DAN PEMBAHASAN}

Dari hasil penelitian ini adalah alat bantu stoper penahan hand jig. Dari usulan yang sudah diberikan, untuk menangulangi masalah yang timbul peneliti harus segera menentukan perbaikan yang sudah ditetapkan. Dalam hal ini Alternatif design model alat B menjadi pilihan yang tepat, dikarena alternatif B memiliki 2 magnet sebagai penahan kedudukan fender agar posisinya tetap dan tidak bergeser. Sedangakan pada Alternatif design model alat A menggunakan 1 magnet sebagai penahan fender, hal ini dirasa kurang efektif dikarenakan pada bagian rocker panel tidak ada pehanan fender. Sehingga dapat membuat fender bergeser dan membuat fitting menjadi NG. selain itu dalam penggunaan alat ini mempermudah proses dalam setting part fender dan menjaga kedudukan fender agar tidak bergeser ketika proses tightening bolt.

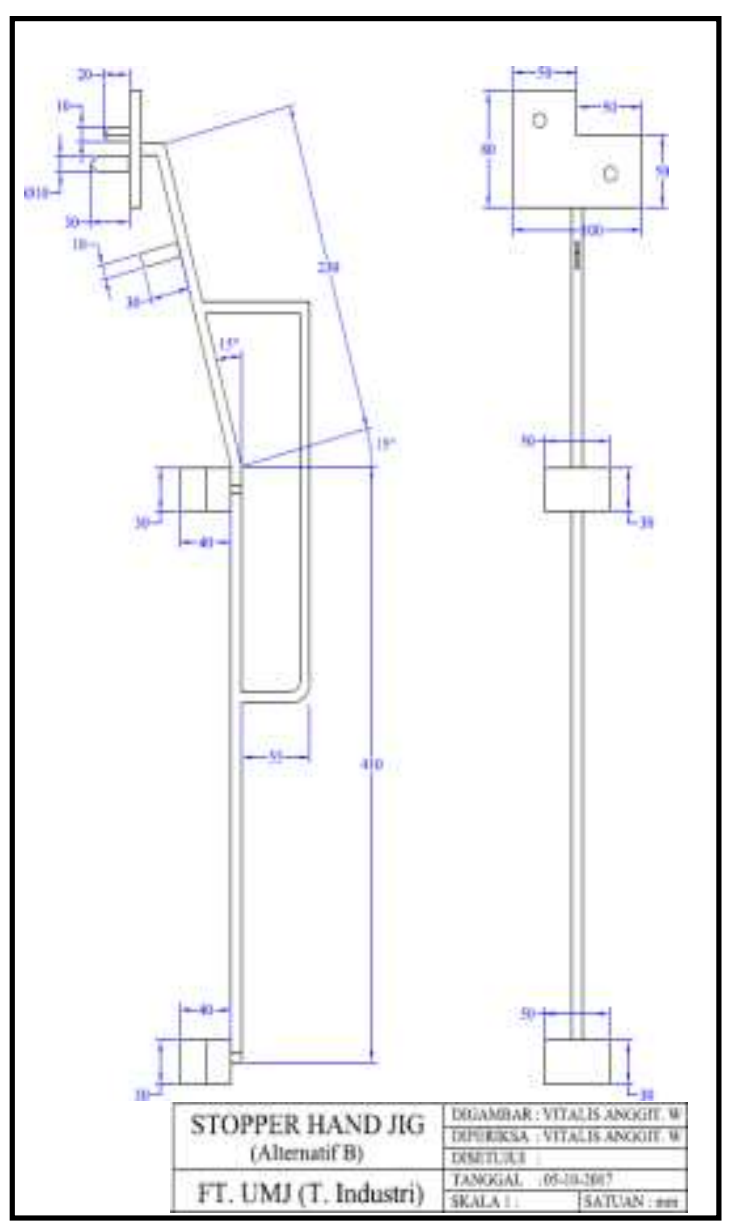

\section{KESIMPULAN}

Berdasarkan pengolahan data dan hasil analisis yang telah dilakukan pada penelitian ini, maka dapat ditarik kesimpulan sebagai berikut :

1. Penyebab utama defect fender Lh bump impact fitting adalah sebgai berikut:

\section{a) Machine}

1. Proses yang yang kurang standar dari tools yang digunakan sehingga body sniper toucing dengan rocker panel. Hal ini diakibatkan karena socket M6 yang kurang standart dari proses pemasangan fender. 
2. Clamp hand jig bergoyang yang diakibatkan tidak adanya stoper pada hand jig fender, sehingga pada saat pemasangan fender kondisi fender menjadi tidak akurat dan masuk kedalam yang menyebabkan hasil fitting NG. Dan memerlukan proses repair yang menyebabkan defect benjol pada fender.

\section{b) Methode}

Proses repair fitting dihentakan sehingga menimbulkan defect benjol pada area fender. Mengingat fender adalah single part yang memiliki ketebalan 0,67 mm, jadi ketika adanya hentakan akan membuat defect pada permukaan fender.

\section{c) Enviropment}

Cahaya penerangan tidak maksimal sehingga pada saat repair fitting pada gap fender tidak terlihat jelas hal ini disebabkan karena lampu kurang terang.

2. Bedasarkan hasil penelitian yang sudah dilakukan, metode untuk menurunkan defect fender Lh bunp impact fitting adalah sebgai berikut:

a) Mengganti socket M6 yang berukuran $100 \mathrm{~mm}$ dengan ukuran $200 \mathrm{~mm}$ agar pada saat proses pemasangan fender pada area rocker panel, body sniper tidak touching dengan rocker panel yang menyebabkan fitting fender NG.

b) Dibuatkan stoper penahan hand jig fender yang berfungsi untuk menjaga posisi fender dari pergeseran ketika proses pemasangan bolt M6. Tujuan agar proses repair fitting tidak dihentakan yang berpotensi meyebabkan defect fender bump impact fitting.

c) Dibuatkan standar proses repair fitting yang benar dan melakukan revisi perbaikan pada SOP.

d) Menambah dan mengganti lampu yang sudah tidak layak, hal ini bertujuan agar proses repair fitting terlihat jelas.

3. Setelah dilakukan perbaikan dari hasil penelitian, menunjukan bahawa dengan adanya penanggulangan permasalahan defect fender Lh bump impact fitting unit D17D telah berhasil

menurunkan atau mengurangi defect sebesar 294 menjadi 4 pada bulan Desember 2017.

\section{Saran}

Adapun saran yang akan diberikan dari penelitian ini kepada perusahaan agar dapat meningkatkan perbaikan kualitas adalah sebagai berikut:

1. Melakukan pengawasan dan pembaharuan terhadap SOP dan prosedur di Body Welding yang sudah tidak sesuai dengan perubahan take time yang baru agar dapat mencegah timbulnya kesalahan-kesalahan karena kelalaian yang dilakukan oleh team member atau operator.

2. Seorang Leader harus lebih aktif dalam menjaga dan meningkatkan kerjasama antar team member dalam rangka memperlancar proses produksi.

3. Ketika team member mengalami kondisi abnormal sebaiknya segera memberi informasi kepada atasan agar atasan segera melakukan action untuk mengatasi kendala yang timbul.

UCAPAN TERIMAKASIH 
dapat terselesaikan.

1. Ibu Renty Anugerah M.P. ST., MT. Selaku ketua jurusan Teknik Industri Universitas Muhammadiyah Jakarta.

2. Ibu dan Bapak Dosen Jurusan Teknik Industri Universitas Muhammadiyah Jakarta yang telah memberi bekal ilmu kepada penulis selama masa kuliah.

3. Rekan mahasiswa teknik industri FT.UMJ angkata 2013 yang telah banyak memberikan dorongan sepiritual baik lahir maupun batin sehingga penulis dapat menyusun skripsi hingga selesai.

4. Keluarga besar yang selalu mendoakan lahir batin dan tetap menyemangati jerih payah dan usaha selama ini.

5. Bapak Wakris, ST. selaku pembimbing lapangan Body Welding PT XYZ.

6. Kepada semua pihak yang telah membantu penulis dalam proses penulisan laporan kerja praktek ini yang tidak mungkin disebutkan satu - persatu.

7. Kepada Ibu Elizabet Erna Widhowati dan Bapak Sugeng Santoso sebagai orang tua saya yang selalu mendukung dan menjadi inspirasi bagi hidup saya.

8. Kepada istri saya Nur Laily Prabandari, SE. yang selalu mensupport dan senantiasa memberikan masukan dalam pembuatan Tugas Akhir ini.

9. Kepada anak Alfostra Xevan Wicaksono yang menjadi penyemangat dalam menuntut ilmu.

\section{DAFTAR PUSTAKA}

Dr Indasah,Tr. M Kes, Sanitasi industri Dan kesehatan Keselamatan Kerja,

Pendidikan Deepublish, 2017.
Gaspersz, Vincent, All in one management toolbook, Jakarta, Gramedia

Pustaka Utama, 2012.

Nasution, M, Nur, M.Sc.,APU, Manajemen Mutu Terpadu, Graha

Indonesia, 2014.

Paliska, D Pavletic, M Sokovic, Jurnal Of Mechanical Engineering, 2007.

Jong Feliand Yonatan ${ }_{2}^{1}$ Herry Christian $\quad \mathrm{alit}^{2}$, Upaya Meningkatkan Kualitas PartUpper Cover Dengan Metode PDCA Di PT Astra Komponen Indonesia, 2014.

Saifuddin Bachrun, Desain Pengupahan Untuk Perjanjian Kerja Bersama,

PPM, 2015.

Tannady, Hendy, Pengendalian Kualitas Universitas Bunda Mulia, Graha

Ilmu, 2015 